\title{
ORIGINAL
}

\section{EFECTOS ADVERSOS ASOCIADOS A LA VACUNACIÓN ANTIGRIPAL EN PEDIATRÍA}

\author{
Vicente Martín Moreno (1), María del Rosario Molina Cabrerizo(2), María Jesús Sotillo \\ Rincón(3), Carlos Gómez Gómez (4) y Julia Alvarez Gómez (2).
}

(1) Centro de Salud San Fernando II. Azorín. Móstoles. Madrid.

(2) Centro de Salud de Navalcarnero, Navalcarnero, Madrid.

(3) Centro de Salud de Humanes, Humanes, Madrid.

(4) Hospital Gregorio Marañón. Madrid.

\section{RESUMEN}

Fundamento: las dificultades para valorar adecuadamente la morbimortalidad por gripe en la infancia y las limitaciones de la propia vacuna, hacen que su uso en esta etapa siga siendo limitado. El objetivo del presente estudio es valorar los efectos adversos asociados a la vacunación antigripal en niños.

Material y métodos: estudio prospectivo realizado en las campañas 92/93, 93/94 y 97/98 en 105 niños de Navalcarnero, con vacuna antigripal de virus fraccionados e inactivados con las cepas vacunales recomendadas por la OMS. Todas las dosis son administradas por una enfermera, que también realiza los controles postvacunales a las 72 horas. Se valoran los efectos adversos, la zona de inyección, el sexo, la edad, la vacunación previa y el recoger los datos por teléfono o en consulta.

Resultados: de forma global, en 318 dosis administradas, a nivel local aparece reacción en el $10,7 \%$, en forma de eritema $(8,5 \%)$, induración $(7,9 \%)$ y dolor (sólo $97 / 98,13,9 \%$ ) y a nivel sistémico en el $11,9 \%$, en forma de rinorrea $(3,1 \%)$, malestar general $(2,5 \%)$, fiebre $(2,5 \%)$, dolores musculares $(1,6 \%)$ y tos $(1,6 \%)$. El $89.5 \%$ de los efectos sistémicos desaparecen en las primeras 48 horas. Ningún caso precisó consulta médica.

Conclusiones: la vacuna es segura. Los efectos adversos que aparecen son escasos, leves y bien tolerados. No existen diferencias significativas en función de la edad, el sexo, la vacunación previa o el hecho de recoger los resultados por teléfono o en consulta. La zona glútea presenta mayor reactogenicidad local que lia zona deltoided.

Palabras clave: Gripe. Vacuna antigripal. Infancia. Influenza. Inmunizaciones. Vacuna de virus fraccionados.
Correspondencia

Vicente Martín Moreno

Calle del Alerce, 5, 5. ${ }^{\circ} \mathrm{B}$

28041 Madrid

Teléfono: (91) 6111161

\section{ABSTRACT}

\section{Safety and Tolerability of Split-Virion Influeza Vaccine in Spanish Children}

Background: the difficulties which exist in order to value correctly the morbimortality caused by influenza during the childhood and the limitations of the proper vaccine make that the use of this vaccination is still limitated in this phase. The objective of the present study is to value the adverse reactions associated to the influenza immunization in children.

Methods: prospective study, carried out in the campaigns 92/93, 93/94 97/98 on 105 children of Navalcamero with splitvirion influenza vaccine with vaccunal strains recommended by the OMS. All the doses are administered by a nurse who also carries out the postimmunization-controls after 72 hours. The adverse reactions are valued, like the zone of injection. sex. age, the previous vaccination and the collection of data by telephone or in consultation.

Results: of global form (318 doses), on a local level appears a reaction of $10,7 \%$, in form of erythema $(8,5 \%)$, induration $(7,9 \%)$ and pain (only $97 / 98,13,9 \%)$ and on a systemic level appears a reaction of $11,9 \%$, in form of rhinorrhea $(3,1 \%)$. general discomfort $(2,5 \%)$, fever $(2,5 \%)$, muscular pains $(1,6 \%)$ and cough $(1,6 \%)$. In a $89.5 \%$ the systemic effects disappear during the first 48 hours. In no case medical consultation was precised.

Conclusions: the vaccine is safe. The adverse reactions that may appear arc searce, slight and well tolcrated. There do not exist significant differences in terms of age, sex, the previous vaccination or the collection of the results by telephone or in consultation. The gluteus presents greater local reactogenicity that the deltoidal zone.

Key words: Influenza. Influenza vaccine. Children. Immunization. Split-virion vaccine. 


\section{INTRODUCCIÓN}

$\mathrm{El}$ agente causal de la gripe en el hombre es un virus perteneciente a la familia Orthomyxoviridae (RNA), del que existen tres tipos serológicos, A, B y C, en función de la propiedad de su nucleocápsida de fijar el complemento. La nucleocápsida está envuelta por una capa lipoproteica de la que emergen espículas proteicas de dos tipos: hemaglutinina $(\mathrm{H})$ y rleuraminidasa $(\mathrm{N})$. Los virus $A$ y $B$ contienen hemaglutinina y neuraminidasa y el virus $C$ no tiene neuraminidasa. A su vez, tanto la hemaglutinina como la neuraminidasa presentan variantes antigénicas que permiten la clasificación en diversos subtipos. En concreto, el virus gripal A tiene 15 hemaglutininas $\left(\mathrm{H}_{1}\right.$ a $\left.\mathrm{H}_{15}\right)$ y 9 neuraminidasas $\left(N_{1}\right.$ a $\left.N_{9}\right)$ antigénicamente diferentes, mientras que para el virus gripal $B$, que también muestra diferencias en estos dos antígenos, aún no se ha realizado una subclasificación'.

Los virus gripales A están sujetos a dos tipos de cambios antigénicos ${ }^{2}$ : la deriva antigénica (antigenic drift), que es frecuente y se debe a mutaciones puntuales del genoma, que constituyen un cambio menor; queda registrada añadiendo el lugar del aislamiento, el número de la cepe. estudiada y el año en que se descubrió a las referencias habituales de la inicial del tipo de virus y el subtipo de hemaglutinina y neuraminidasa (por ejemplo, A/Beijing/353/89 $\left(\begin{array}{ll}\mathrm{H}_{3} & \left.\mathrm{~N}_{2}\right)\end{array}\right.$ quiere expresar que el subtipo gripal $\mathrm{A}\left(\mathrm{H}_{3}\right.$ $\mathrm{N}_{2}$ ) fue aislado en el año 1989 en Beijing y la cepa estudiada fue la 353 ). El segundo cambio es el desplazámiento antigénico (antigenic shift), que es menos frecucnte y constituye un cambio mayor, al producirse la aparición de la $\mathrm{H}$ y/o $\mathrm{N}$ diferentes antigénicamente de los precedentes. Cada 10-40 años se producen pandemias intensas del virus gripal A como consecuencia del desplazamiento antigénico. Posteriormente, cada 2-3 años se producen epidemias, generalmente de menor intensidad, asociadas con la deriva antigénica. Excepción a la regla, a finales de 1977 apareció el subtipo
$\mathrm{H}_{1} \mathrm{~N}_{1}$, que sin embargo no desplazó, como estaba previsto, al $\mathrm{H}_{3} \mathrm{~N}_{2}$ previo, por lo que desde esa fecha ambos han causado enfermedad epidémica y por ello ambos figuran en la composición vacunal, con los cambios puntuales asociados a la deriva antigénica. En 1997 se han detectado algunos casos de gripe $A$ por un nuevo subtipo ${ }^{3}, \mathrm{H}_{5} \mathrm{~N}_{1}$, cuya evolución va a ser objeto de un exhaustivo seguimiento. Las actuaciones preventivas para el control de la enfermedad por virus gripal A se ven dificultadas por la variabilidad antigénica del virus y la posibilidad de recombinaciones con virus gripales animales ${ }^{4.5}$.

Los antígenos $\mathrm{H}$ y $\mathrm{N}$ del virus gripal $\mathrm{B}$ no están tan bien caracterizados como los del A. pero se conocen cepas antigénicamente diferentes. El virus gripal B experimenta deriva antigénica, que se referencia igual que para el virus $A$, pero no se ha demostrado desplazamiento antigénico. Los brotes principales de gripe $B$ son más variables, pero suelen ocurrir a intervalos de 4 a 7 años.

El virus gripal $C$ no presenta variaciones. La gripe producida por este virus rara vez se detecta, probablemente porque produce manifestaciones de catarro común poco alarmantes; aunque no se han determinado los patrones epidemiológicos del virus gripal C, la mayoría de los niños presentan anticuerpos frente a dicho virus a los 10 años.

Los datos sobre la gripe no complicada en niños son escasos, al ser habitualmente una enfermedad benigna que cura sin secuelas ${ }^{6}$; el diagnóstico en la mayoría de los casos es de sospecha y sólo durante los brotes epidémicos que afectan a toda la comunidad se suele llegar a establecer la etiología mediante serologías. Las manifestaciones clínicas de la gripe por virus A y B son similares, aunque en función de la edad la clínica varía: en los niños mayores y adolescentes es similar a la del cuadro gripal del adulto, mientras que en los pequeños es similar a la de otros virus respiratorios y puede dar lugar a larin- 
gotraqueitis, bronquitis, bronquiolitis y neumonía además del resfriado común.

La mayoría de las complicaciones de la gripe, como hemos apuntado, son variantes del cuadro respiratorio inicial. Con mucha menor frecuencia pueden aparecer miositis, parotiditis, crup grave, neumonía hemorrágica, encefalitis y otros síndromes neurológicos, miocarditis, síndrome de Reye, síndrome de muerte súbita del lactante, mioglobinuria y, algo más frecuentes, complicaciones secundarias por sobreinfección bacteriana (otitis, sinusitis, traqueitis, neumonía). La miositis aguda, que aparece a la semana de iniciarse el cuadro respiratorio y afecta a gemelos y sóleo, se asocia generalmente con el virus $\mathrm{B}^{7,8}$.

La inmunización infantil con vacunas de virus de la gripe fraccionados inactivados es segura y efectiva, aunque su administración rutinaria no está recomendada ${ }^{9,10}$ y se reserva exclusivamente para los grupos de riesgo aceptados por la Organización Mundial de la Salud (OMS) y las autoridades sanitarias de cada estado. El objetivo planteado es analizar la seguridad y tolerancia de la vacuna antigripal de virus fraccionados inactivados en la edad pediátrica.

\section{SUJETOS Y MÉTODOS}

Se trata de un estudio prospectivo que incluye a 105 niños de la Zona Básica de Salud de Navalcarnero, población rural de la Comunidad Autónoma de Madrid (CAM), realizado en los intervalos septiembre de 1992 - noviembre de 1992, septiembre de 1993 -noviembre de 1993 y septiembre de 1997 -noviembre de 1997.

Se utiliza vacuna de virus fraccionados inactivados, conteniendo las cepas recomendadas ${ }^{11}$ para cada campaña por la OMS:

- 92/93: vacuna antigripal Pasteur ${ }^{\circledR}$, con A/Beijing/353/89 $\left(\mathrm{H}_{3} \mathrm{~N}_{2}\right)$; A/Singapo$\mathrm{re} / 6 / 86\left(\mathrm{H}_{1} \mathrm{~N}_{1}\right)$ y $\mathrm{B} /$ Yamagata/16/88.
- 93/94: vacuna antigripal Pasteur ${ }^{\circledR}$, con A/Beijing/32, $92 \quad\left(\mathrm{H}_{3} \mathrm{~N}_{2}\right)$; A/Singapore/6/86 $\left(\mathrm{H}_{1} \mathrm{~N}_{1}\right)$ y B/Panamá/45/90.

- 97/98: Mutagrip ${ }^{\circledR}$ (fabricada por Pasteur-Merieux), con cepa análoga $\mathrm{A} / \mathrm{Wu}-$ ham/359/95 $\left(\mathrm{H}_{3} \mathrm{~N}_{2}\right)(\mathrm{A} / \mathrm{Nanchang} / 933 /$ 95)-RESVIR 9; cepa análoga A/Bayern/ $7 / 95\left(\mathrm{H}_{1} \mathrm{~N}_{1}\right)(\mathrm{A} / \mathrm{J}$ ohannesburg/82/ 96)NIB 39 y cepa análoga B/Beijing/ 184/93 (B/Harbin/7/94).

Con tiomersal como conservador (máximo $0,05 \mathrm{mg}$ ) y exc piente c.p.s. $0,5 \mathrm{ml}$. Cada dosis de $0,5 \mathrm{ml}$ contiene 15 microgramos de cepa de cada virus, expresado en hemaglutininas. La vía de administración es intramuscular. Dentro de cada campaña se utiliza sólo un lote vacunal.

Para niños de 21 a 35 meses se pautan dos dosis de $0,25 \mathrm{ml}$ y para niños de 3 a 8 años dos dosis de $0,5 \mathrm{ml}$, administradas con un intervalo de cuatro semanas. Para niños vacunados en campañas anteriores, una sola dosis adecuada a su edad.

La actividad se realiza en consulta programada de enfermería, informando a los padres sobre motivo de la vacunación, qué efectos adversos deben valorar en sus hijos tras la vacuna y medidas a tomar en caso de que aparezcan, a la vez que se les instruye para que observen y apunten durante 72 horas, la intensidad y duración de los síntomas si aparecieran. Se obtiene consentimiento oral informado para la administración y para las variaciones en la zona de inyección. Todas las dosis son administradas por la misma enfermera, que también realiza el seguimiento postvacunal y la cumplimentación de la encuesta a los padres a las 72 horas, que queda recogida en un cuestionario diseñado al efecto. Los padres deben comunicar por teléfono o en consulta, toda reacción inusual o que ocurra por encima de las 72 horas, para su control y evaluación.

La muestra incluye los grupos de riesgo establecidos por la OMS, pero también se incluye en ella a niños que, como consecuen- 
cia de infecciones respiratorias de repetición en el año previo, han sufrido un elevado absentismo escolar y otras patologías en las que el proceso gripal podría potencialmente interferir con la adecuada evolución del niño (peso y/o talla por debajo del $\mathrm{P}_{3}$, enfermedad celiaca, hernia de hiato, reflujo gastroesofágico, anemia, talasemia ${ }^{12}$ ).

Los efectos adversos locales o sistémicos valorados son los que se recogen en la ficha técnica de la vacuna utilizada en el estudio. El eritema y la induración se consideran valorables a partir de $0,5 \mathrm{~cm}$. En la campaña 97/98 se valora también como reacción local el dolor o hipersensibilidad en el punto de inyección. Entre los sistémicos, se considera fiebre la temperatura corporal axilar mayor de $38^{\circ} \mathrm{C}$ y febrícula la temperatura entre 37,5 y $37,9^{\circ} \mathrm{C}$.

En la campaña 92/93 la muestra quedó formada por 105 niños de 21 meses a 8 años, $52(49,5 \%)$ varones y $53(50,5 \%) \mathrm{mu}$ jeres. Se administraron 105 dosis iniciales y 50 segundas dosis, todas en la zona deltoidea. Los padres contactaron por teléfono con el Centro de Salud a las 72 horas, para cumplimentar cuestionario de efectos adversos. En la tabla 1 se recoge la distribución de la muestra por año de nacimiento.

En la campaña 93/94 formaron la muestra 94 niños ya vacunados el año anterior. Se dividió la muestra en dos grupos, según se realizara el control de las 72 horas por teléfono o en consulta. En el grupo a controlar en consulta se escogen dos zonas de administración, glúteo y deltoides, para valorar la influencia de este parámetro en la aparición de reacción. La distribución hacia cada uno de los tres grupos finales (teléfono, consulta-glúteo y consulta-deltoides) se realizó de forma secuencial (5-10-5), obteniendo de forma aleatoria la asignación del primero a uno de ellos. Se establecieron además dos grupos control: uno $(n=35)$ con la totalidad de los que iniciaban en ese año la vacunación antigripal, con administración en deltoides y control en consulta, para valorar diferencias de reactogenicidad con los grupos consulta-deltoides y consulta-glúteo de los revacunados; y otro con niños adscritos a otra consulta $(n=21)$, en el que las dosis son administradas por otra enfermera en deltoides y el control se realiza en consulta, para analizar diferencias de reactogenicidad atribuibles a la técnica.

En la campaña 97/98 la muestra estuvo formada por 44 niños que seguían adscritos a la consulta, habían sido vacunados cada año desde la campaña 92/93, mantenían criterio de vacunación y su administración no coincidía con la vacuna frente a la meningitis $\mathrm{A}+\mathrm{C}$, cuya campaña se desarrolló paralelamente a la antigripal en la CAM. Todas las dosis fueron administradas en zona deltoidea y el control se realizó en consulta a las 72 horas.

Para el análisis estadístico de los datos se utilizaron los test chi-cuadrado y chi-cuadrado para comparación de proporciones independientes. Si existía una o más celdas con valor esperado menor o igual a 5, se empleaba el test de la probabilidad exacta de Fisher. Mediante el análisis de la varianza y el test de la t de Student comprobamos que no existían diferencias significativas en la media de edad de cada sexo. Consideramos que las diferencias observadas tenían significación estadística cuando $\mathrm{p}<0,05$.

Tabla 1

Distribución de la muestra estudiada por año de nacimiento

\begin{tabular}{|lcrrrrrrr|}
\hline Sexo/año nac. & 1984 & 1985 & 1986 & 1987 & 1988 & 1989 & 1990 & 1991 \\
\hline Varón & 1 & 9 & 8 & 9 & 7 & 10 & 8 & 0 \\
Mujer & 0 & 7 & 10 & 7 & 15 & 7 & 6 & 1 \\
Total & 1 & 16 & 18 & 16 & 22 & 17 & 14 & 1 \\
\hline
\end{tabular}




\section{RESULTADOS}

\section{Primera dosis 92/93}

El $100 \%$ de los padres llamó a las 72 horas para cumplimentar la encuesta. El $24,8 \%$ de los niños presentó algún efecto adverso, en forma de reacción local $(10,5 \%$ de los vacunados) o general $(18,1 \%)$; el $3,8 \%$ presentó reacción a ambos niveles. Por sexos, el 18,9\% de las niñas y el 30,8\% de los niños presentó algún efecto secundario, sin que la diferencia fuera estadísticamente significativa.

A nivel local, el $9,5 \%$ de los vacunados presentó enrojecimiento y el $6,7 \%$ induración. El 5,7\% tuvo ambas reacciones. En ningún caso el eritema o la induración superaron los $2 \mathrm{~cm}$. El 36,4\% de los vacunados que presentaron reacción local fueron niñas y el $63,6 \%$ varones.

A nivel sistémico, los efectos adversos presentados fueron: malestar general $(4,8 \%$ de los vacunados), febrícula $(4,8 \%)$, dolores musculares $(3,8 \%)$, rinorrea $(3,8 \%)$, fiebre $(2,8 \%)$, tos $(1,9 \%)$, exantema-reacción urticarial dudosa $(1,9 \%$, leve, no requirió consulta médica), cefalea (1\%) y vómitos $(1 \%)$. El $36,8 \%$ de los vacunados que presentaron reacción general fueron niñas y el $63,2 \%$ niños.
No hubo diferencias estadísticamente significativas en los resultados obtenidos en función de la edad o el sexo (tabla 2). En el $84,6 \%$ de los casos los efectos sistémicos desaparecieron en las primeras 24 horas, en el $11,5 \%$ entre las 24 y 48 horas y en el $3,9 \%$ se mantuvieron por encima de este intervalo de tiempo. El 19,2\% de los niños que prescntaron algún efecto adverso precisó la administración de un analgésico-antitérmico. En ningún caso se requirió consulta médica dentro de las 72 horas postvacunales. Los dos casos referidos como urticaria no presentaban lesiones a las pocas horas, por lo que los padres no solicitaron consulta médica, no siendo posible, por ello, evaluar el tipo de lesión presentada; en todo caso, desaparecieron espontáneamente y sin medicación.

\section{Segunda dosis $92 / 93$}

De los 51 niños a los que correspondía administrar segunda dosis acudieron 50. De ellos, el $8 \%$ fue vacunado, pero no llamaron para comunicar los resultados, ni fueron localizados. Sobre los niños controlados, tabla 3 , el $17,4 \%$ presentó algún efecto secundario, en forma de reacción local en el $8,7 \%$ y de rcacción general en el 10,9\%. El 2,2\% presentó ambos tipos de reacción.

Tabla 2

Incidencia de efectos adversos tras la primera dosis de vacuna — $92 / 93$ — en función del año de nacimiento (edad) y sexo.

\begin{tabular}{|cccccccccc|}
\hline \multirow{2}{*}{ Campaña $92 / 93(n=105)$} & \multicolumn{3}{c}{ No reacción } & \multicolumn{3}{c}{ Reacción local } & \multicolumn{3}{c|}{ Reacción general } \\
\cline { 2 - 10 } & varón & mujer & total & varón & mujer & total & varón & mujer & total \\
\hline 1984 & 1 & 0 & $\mathbf{1}$ & 0 & 0 & $\mathbf{0}$ & 0 & 0 & $\mathbf{0}$ \\
1985 & 6 & 5 & $\mathbf{1 1}$ & 3 & 2 & $\mathbf{5}$ & 1 & 0 & $\mathbf{1}$ \\
1986 & 4 & 8 & $\mathbf{1 2}$ & 1 & 1 & $\mathbf{2}$ & 3 & 2 & $\mathbf{5}$ \\
1987 & 7 & 7 & $\mathbf{1 4}$ & 2 & 0 & $\mathbf{2}$ & 1 & 0 & $\mathbf{1}$ \\
1988 & 7 & 12 & $\mathbf{1 9}$ & 0 & 1 & $\mathbf{1}$ & 0 & 2 & $\mathbf{2}$ \\
1989 & 5 & 5 & $\mathbf{1 0}$ & 1 & 0 & $\mathbf{1}$ & 5 & 2 & $\mathbf{7}$ \\
1990 & 6 & 6 & $\mathbf{1 2}$ & 0 & 0 & $\mathbf{0}$ & 2 & 0 & $\mathbf{2}$ \\
1991 & 0 & 0 & $\mathbf{0}$ & 0 & 0 & $\mathbf{0}$ & 0 & 1 & $\mathbf{1}$ \\
\hline TOTAL & 36 & 43 & $\mathbf{7 9}$ & $\mathbf{7}$ & 4 & $\mathbf{1 1}$ & 12 & $\mathbf{7}$ & $\mathbf{1 9}$ \\
\hline
\end{tabular}


A nivel local, el 8,7\% presentó enrojecimiento y el $6,5 \%$ induración; ambos efectos adversos locales aparecieron en el 6,5\%. En ningún caso el eritema o la induración superaban los $2 \mathrm{~cm}$. Como efectos adversos a nivel sistémico aparecieron: rinorrea $(6,5 \%)$, tos $(4,3 \%)$, fiebre $(2,2 \%)$ y malestar general $(2 \%)$.

En el $100 \%$ de los casos los efectos adversos sistémicos desaparecieron en las primeras 48 horas. El $37,5 \%$ de los vacunados que presentó algún tipo de reacción fueron niñas y el $62,5 \%$ niños. No existieron diferencias significativas en la incidencia de efectos adversos a nivel local o sistémico entre la primera y la segunda dosis ni tampoco con esta segunda dosis en función del sexo.

\section{Revacunación 93/94}

En la campaña 93/94 se procedió a la revacunación de 94 niños. Globalmente (tabla 3 ) el $15,4 \%$ presentó algún efecto adverso, en forma de reacción local (11\%) o general $(5,5 \%)$. El 1,1\% presentó reacción local y general.

En el grupo de contacto por teléfono $(\mathrm{n}=26$, administración en glúteo), todos los padres llamaron a las 72 horas. El 11,5\% de los niños presentó algún efecto adverso: el $7,69 \%$ local en forma de enrojecimiento e induración, y el 7,69\% general en forma de fiebre, sin otra sintomatología. El 3,8\% muestra a la vez ambos tipos de reacción.

En el grupo de control en consulta y administración en zona glútea $(n=48)$ el $6,2 \%$ no acudió, no pudiendo tampoco ser localizados por teléfono, por lo que desconocemos su evolución. Presentó reacción local a las 72 horas el $17,8 \%$, en forma de induración el $6,7 \%$ y en forma de induración y enrojecimiento el $11,1 \%$ restante. El $4,4 \%$ presentó reacción general, como rinorrea $(2,2 \%)$ y fiebre $(2,2 \%)$. En ningún caso se produce presentación simultánea de reacción local y general.
En el grupo de seguimiento en consulta y administración en zona deltoidea $(n=20)$ a las 72 horas no presentó reacción local ningún vacunado. El $5 \%$ presentó reacción gcneral, en forma de rinorrea. En el grupo control que inició ese año la vacunación $(n=35)$, el 5,7\% no acudió, el $6,1 \%$ presentó algún efecto adverso sistémico y el $3 \%$ reacción local. No existen diferencias significativas entre ambos grupos.

La presencia a las 72 horas en consulta de reacción local tras la administración de vacuna antigripal es más elevada cuando se realizó en zona glútea que cuando se realizaba en deltoides ( $p=0,0427$ y $p=0,039$ respectivamente respecto a revacunados-deltoides e inicio vacunación-deltoides). En el $100 \%$ de los casos los efectos secundarios generales desaparecieron en las primeras 48 horas, no precisando consulta médica. En ningún caso el eritema o la induración superaron los $2 \mathrm{~cm}$. Comparando los resultados globales de esta campaña y los relativos a la primera dosis $92 / 93$, la presencia de reacción sistémica es inferior $(\mathrm{p}<0,01)$, sin que existan diferencias con la segunda dosis $92 / 93$ o a nivel local y tampoco por el hecho de recoger los resultados por teléfono o en consulta.

Respecto al grupo control vacunado por otra enfermera $(n=21)$, el $57,1 \%$ fueron niños y el $42,9 \%$ niñas. En el $11,8 \%$ aparece reacción local y en el $23,5 \%$ reacción general. La incidencia de efectos adversos a nivel local no difiere significativamente entre este grupo y los grupos consulta-deltoides del estudio primario.

\section{Revacunación 97/98}

Se vacunó a 44 niños, de los que el 52,3\% son varones y el $47,7 \%$ mujeres. El $2,3 \%$ no acude a control. Sobre niños controlados, el $25,6 \%$ presentó algún efecto adverso, a nivel local $(18,6 \%)$ o sistémico (16,3\%); el 9,3\% a ambos niveles. 
A nivel local presentaron a las 72 horas enrojecimiento el 11,6\%, induración el $9,3 \%$ y dolor en la zona de inyección el 13,9\%. En el $80 \%$ de los casos el eritema y/o la induración superaron $\operatorname{los} 2 \mathrm{~cm}$.

A nivel sistémico aparecieron cefalea $(9,3 \%)$, malestar general $(4,6 \%)$, rinorrea $(2,3 \%)$, dolores musculares $(2,3 \%)$, exantema de breve duración que no se mantuvo hasta poder ser valorado en consulta $(2,3 \%)$, y tos $(2,3 \%)$. En el $57,1 \%$ de los casos los efectos adversos a nivel sistémico desaparecieron en las primeras 24 horas, en el 14,3\% entre las 24 y 48 horas y en el $28,6 \%$ persistieron por encima de este intervalo temporal. El $7 \%$ requirió medicación analgésica-antitérmica.

Comparando los resultados de la primera dosis $92 / 93$, segunda dosis 92/93, revacunación 93/94 y revacunación 97/98, tabla 3, comprobamos que las diferencias presentadas no eran estadísticamente significativas, por lo que la revacunación a los 5 años de iniciar el estudio no aumenta la incidencia de efectos adversos a nivel local o sistémico.

De forma global, sumando los datos sobre efectos secundarios de las $318 \mathrm{vacu-}$ nas administradas y controladas por la misma enfermera en las cuatro fases analizadas, el $10,7 \%$ (34) presentaron reacción local y el $11,9 \%$ (38) reacción general; en el 3,1\% (10) ambos tipos de reacción aparecieron a la vez. Los efectos adversos a nivel sistémico más frecuentes fueron: rinorrea: $3,1 \%(10)$; malestar general: $2,5 \%$ (8); fiebre: $2,5 \%$ (8); febrícula: $1,9 \%(6)$; dolores musculares: $1,6 \%(5)$; y tos: $1,6 \%$ (5). En el 89,5\% (34) de los casos los efectos adversos sistémicos desaparecieron en las primeras 48 horas y en el $8,3 \%$ (3) se mantuvieron más alla de este período. El $3,1 \%$ (10) requirió medicación. Ningún caso precisó consulta médica.

\section{DISCUSIÓN}

Al tratarse de niños incluidos en grupos de riesgo, por razones éticas no se ha establecido un grupo control con placebo, por lo que desconocemos qué porcentaje de efectos adversos sistémicos se deben a una excesiva observación de los padres o a la presencia de procesos intercurrentes en los días posteriores a la vacunación. No obstante, el hecho de que no existieran diferencias significativas en la incidencia de dichos efectos entre la primera y la última fases del estudio, cuando entre ambas median 5 años, y el que los

Tabla 3

Datos globales de las diversas campañas.

\begin{tabular}{|c|c|c|c|c|c|c|c|c|c|}
\hline \multirow[t]{2}{*}{ Comparación dosis/campañas } & \multicolumn{3}{|c|}{ No reacción } & \multicolumn{3}{|c|}{ Reacción local } & \multicolumn{3}{|c|}{ Reacción general } \\
\hline & varón & mujer & total & varón & mujer & total & varón & mujer & total \\
\hline Primera dosis $92 / 93(n=105)$ & 36 & 43 & 79 & 7 & 4 & 11 & 12 & 7 & 19 \\
\hline Segunda dosis $92 / 93 \quad(n=46)$ & 18 & 20 & 38 & 2 & 2 & 4 & 3 & 2 & 5 \\
\hline \multicolumn{10}{|l|}{ Revacunación 93/94 ( $\mathrm{n}=91)$ : } \\
\hline Consulta/glúteo & 17 & 18 & 35 & 0 & 8 & 8 & 1 & 1 & 2 \\
\hline Consulta/ deltoides & 13 & 6 & 19 & 0 & 0 & 0 & 1 & 0 & 1 \\
\hline Teléfono/glúteo & 14 & 9 & 23 & 1 & 1 & 2 & 1 & 0 & 1 \\
\hline Total & 44 & 33 & 77 & 1 & 9 & 10 & 3 & 1 & 4 \\
\hline Primera dosis $93 / 94(n=33)$ & 19 & 12 & 31 & 0 & 1 & 1 & 1 & 1 & 2 \\
\hline Grupo control $93 / 94(n=21)$ & 7 & 8 & 15 & 1 & 1 & 2 & 4 & 0 & 4 \\
\hline Revacunación $97 / 98(n=43)$ & 19 & 13 & 32 & 3 & 5 & 8 & 1 & 6 & 7 \\
\hline TOTAL & 143 & 129 & 272 & 14 & 22 & 36 & 24 & 17 & 41 \\
\hline
\end{tabular}


resultados se ajustaran a los previamente publicados, hace probable que los sesgos en este sentido sean mínimos.

Se plantea, además, la validez de comparar los resultados obtenidos en las distintas campañas entre sí y con los recogidos en otros estudios, cuando las cepas vacunales o incluso la propia composición de la vacuna antigripal varían de una a otra campaña y la reactogenicidad de las cepas utilizadas en la composición de la vacuna es diferen$\mathrm{te}^{13}$. Parte del estudio realizado no se ve afectado por estas limitaciones, ya que la composición de la vacuna e incluso el lote son los mismos (comparación primera y segunda dosis 92/93; valoración de la zona de inyección y diferencias relativas a la técnica o a la forma de recoger los resultados en el 93/94), pero otra parte sí se ve afectada, por lo que en la interpretación de los resultados es preciso tener en cuenta las diferencias apuntadas.

En la serie controlada la vacuna se ha mostrado segura. La frccuencia de aparición de efectos secundarios es baja, inferior a la de la mayoría de las vacunas del calendario oficial $^{14-16}$ o de uso común en pediatría ${ }^{17-19}$, los que aparecen tienen escasa relevancia clínica y son perfectamente tolerados y su duración es breve en el tiempo, desapareciendo generalmente en las primeras 48 horas. No se produce ninguna reacción de especial relevancia o inusual.

En concordancia con estudios previos ${ }^{20-}$ ${ }^{22}$, la edad o el sexo del paciente no influyen de forma significativa en la presencia de reacción tras la administración de vacuna antigripal de virus fraccionados e inactivados, así como tampoco el hecho de recoger los resultados a través del teléfono o en consulta o las posibles diferencias en relación con la técnica de administración de la vacuna entre una u otra enfermera. La vacunación previa, independientemente del intervalo entre dosis, no predispone a una mayor incidencia de efectos adversos.
Pero sí existen diferencias en cuanto a la zona de inyección, por lo que, en principio, recomendamos no utilizar la zona glútea para la administración de esta vacuna. Esta diferente reactogenicidad local puede estar mediada por el tamaño de la aguja que incorpora la jeringa de la vacuna desde fábrica $(0,5 \times 16(25 \mathrm{G}))$, de forma que la menor longitud respecto a las de uso cotidiano en la vacunación infantil $(0,6 \times 25(23 \mathrm{G}))$ puede propiciar que inadvertidamente se realice una administración subcutánea profunda en los lactantes, o que directamente se haga subcutánea en algunas zonas de inyección en niños más mayores y/o con mayor panículo adiposo $\mathrm{y}$, aunque ambas vías son reconocidas como válidas por el fabricante, la reactogenicidad de la administración subcutánea puede ser mayor que la intramuscular; en este sentido, se ha comprobado con otras vacunas $^{23}$ que al utilizar una aguja de menor longitud se produce eritema e induración más pronunciados.

Globalmente, la incidencia de efectos adversos a nivel sistémico y a nivel local es similar, sin que exista una diferencia tan clara de los sistémicos sobre los locales como la que se recoge en otros estudios ${ }^{22}$. La reactogenicidad local no se incrementó en estos 5 años, con lo que la revacunación no parece inducir a largo plazo una sensibilización local frente a la vacuna. A nivel sistémico la rinorrea $^{22}$ es el efecto adverso más frecuente y a nivel local el dolor en el punto de inyección ${ }^{24}$.

La habitual mayor presencia de efectos adversos en niños que en adultos, recogida también en la ficha técnica de la vacuna, no se produce a nivel sistémico, donde los resultados obtenidos son similares a los observados en adultos ${ }^{25-27}$, mientras que a nivel local tampoco en todos los casos es superior en niños ${ }^{27}$.

La incidencia de efectos adversos sistémicos en niños tras la administración de vacuna con virus fraccionados inactivados, es inferior que con vacuna de virus vivos atenuados ${ }^{13}$. 
Las reticencias para administrar vacuna antigripal a niños, justificadas por la dificultad de valorar adecuadamente la morbimortalidad por gripe en la infancia, por la menor inmunogenicidad de la vacuna en ellos y por la asociación de la vacunación durante la gripe porcina de $1976^{28-30}$ con una mayor frecuencia de síndrome de Guillain-Barré, que posteriormente no sc ha repctido, contrasta con la buena aceptación de los padres hacia esta vacuna ${ }^{31}$. No sólo la totalidad de los padres de niños seleccionados aceptaron que sus hijos formaran parte del estudio, sino que cada año, coincidiendo con las campañas de vacunación antigripal para los adultos, un buen número de padres demanda espontáneamente para sus hijos esta vacuna, aunque estos estén sanos.

La seguridad y tolerancia de la vacuna antigripal de virus fraccionados e inactivados y la buena aceptación por los padres ${ }^{32}$, hace recomendable realizar programas de vacunación antigripal específica para grupos de riesgo pediátricos paralelos a los de los adultos ${ }^{33,34}$. La realización de estudios en niños sobre la seguridad y la inmunogenicidad de las vacunas antigripales disponibles es necesaria.

Es preciso, además, desarrollar nuevas vacunas que sean seguras y tengan mayor capacidad inmunogénica, sobre todo en niños ${ }^{4}$, ya que la gripe es un problema de salud de primer orden. La clevada capacidad del virus para modificar su estructura antigénica y su capacidad para recombinarse con virus gripales animales. hace que la posibilidad de que se produzca una nueva pandemia deba estar siempre presente; situaciones como la de 1918, en la que la mortalidad por gripe fue muy elevada, deben ser evitadas mediante mecanismos internacionales de control de nuevos virus. $\mathrm{La}$ eficacia actual de este control ha permitido detectar en mayo de 1997, en una zona del planeta donde han tenido su origen la mayoría de las pandemias de este siglo (sur de China-sudeste asiático), un nuevo subtipo, $\mathrm{H}_{5} \mathrm{~N}_{1}$, presente en un niño con diagnóstico de síndrome de Reye, neumonía aguda gripal y síndrome de distress respiratorio ${ }^{3} \mathrm{y}$ desenlace fatal, y ha puesto en marcha los mecanismos de alerta de la Organización Mundial de la Salud, al desconocerse el potencial de este nuevo subtipo para producir una pandemia. En este sentido, son útiles las recomendaciones recogidas en una reciente revisión monográfica ${ }^{29.35-50}$, que informa sobre la situación actual y establece las bases para la prevención, detección y actuación frente a una probable pandemia gripal.

\section{AGRADECIMIENTOS}

A la Sra. Elke Thomsen, por su colaboración en la traducción de textos.

\section{BIBLIOGRAFÍA}

1. Cherry JD. Infecciones por virus de la gripe. En: Behrman RE, Kliegman RM, Nelson WE, Vaughan III VC. Nelson. Tratado de Pediatría. Madrid: McGraw-Hill - Interamericana de España; 1993.p. 985-988.

2. Verger G. Gripe. En: Verger Garau G. Enfermedades infecciosas, vol 1. Barcelona: Ediciones Doyma; 1988.p. 283-286.

3. de Jong JC, Claas ECJ, Osterhaus ADME, Webster GR, Lim WL. A pandemic warning? Nature $1997 ; 6651: 554$.

4. Castilla-Curtazar T, Martín-Castilla II, Martín Hernández D. Algunos avances en vacunas. An Esp Pediatr 1994; supl 63: 6-11.

5. Calicó I. Vacunación antigripal. Med Clin (Barna) 1990; 94: 795-796.

6. Chicote Pozo J, Casado de Frías E, Nogales Espert A. «Gripe». Pediatría 3. ${ }^{a}$ edición, vol. 2:, Madrid; 1991.p. 899-903

7. Neipp Lindenau C, Guillem Lanuza F, Vargas Torcal F. Miositis aguda transitoria postgripal. An Esp Pediatr 1988; 28: 153-155.

8. Obando Santaella Y, Moreno García MJ, Alvarez Aldeán J, Alvarez Cordovés MM. Miositis aguda postinfluenza en niños. Aten Primaria 1997; 20: 210-211. 
9. Informe del Comité sobre Enfermedades Infecciosas de la Academia Americana de Pediatría. «Gripe». Libro Rojo de la Academia Americana de Pediatría; 1991.p. 214-219.

10. Informe del Comité sobre Enfermedades Infecciosas de la Academia Americana de Pediatría. Inmunización en situaciones clínicas especiales». Libro Rojo de la Academia Americana de Pediatría; 1991.p. 55

11. Romero Baeza C. Vacunación antigripal: tipos de vacunas y tasas de cobertura. Periodo 1983-1996. Información Terapeútica Sistema Nacional de Salud $1997 ; 21: 41-48$.

12. Mortimer EA. Prevención primaria. En: Behrman RE, Kliegman RM, Nelson WE, Vaughan III VC. Nelson. Tratado de Pediatría. Madrid: McGrawHill - Interamericana de España; 1993.p. 177-184.

13. Gruber WC, Belshe RB, King JC, Treanos JJ, Piedra PA, Wright PF, Reed GW, Anderson E, Newman F, for the National Institute of Allergy and Infectious Diseases Vaccine and Treatment Evaluation Program and the Wyeth-Ayers ca Influenza Vaccine Investigators Group. Evaluation of live attenuated intluenza vaccines in children 6-18 months of age: safety, immunogenicity, and efficacy. J Infect Dis 1996; 173: 1313-1319.

14. Muñiz J, Arístegui J, cobos B, Goiri D, Muñozguren N, Pérez-Legorburu A, Jiménez-Crespo JI, Arrate JP. Estudio de la reactogenicidad de las vacunas difteria, tétanos, tos ferina y polio oral. administradas a niños sanos a la edad de 2,4 y 6 meses. An Esp Pediatr 1994 (supl 63): 168.

15. Baraff LJ, Christopher L, Cody MD, James D, Cherry MD. Reacciones asociadas a la vacuna DTP: análisis del lugar de inyección, marca comercial, reacciones previas y dosis. Pediatrics (ed. española) 1984; 17: 25-30.

16. Phillips CF. Novedades en vacunaciones en 1993. Contemporary Pediatrics 1993; 3: 246-252.

17. Madore DV, Johnson CL, Phipps DC, et al. Safety and immunogenicity response to Haemophilus influenzae type b oligosaccharide-CRM 197 conjugate vaccine in 1-to 6-month-old infants. Pediatrics 1990; 85: 331-337.

18. Booy R, Taylor SA, Dobson SRM, Isaacs D. Sleigth G, Aitken S, et al. Immunogenicity and safety of PRP-T conjugate vaccine given according to the Brtitish accelerate immunization schedule. Arch Dis Child 1992: 67: 475-478.

19. Black SB, Shinefield HR, Fireman B, Hiatt R. Safety, inmunogenicity and efficacy in infancy of oligosaccharide conjugate haemophilus influenzae type b vaccine in a United States Population: posible implications for optimal use. J Infect Dis 1992; 165 (suppl 1) S: 139-143.

20. Khan AS, et al. Comparison of US inactivated split-virus and russian live attenuated, cold adapted trivalent influenza vaccines in russian schoolchildren. J Infect Dis 1996; 173: 453-456.

21. Margolis KL, Nichol KL, Poland GA, Pluhar RE. Frequency of adverse reactions to influenza vaccine in the elderly. A randomized, placebo-controlled trial. JAMA 1990; 264: 1139-1141.

22. Fernández Carazo, C.; Rodríguez Sánchez, M. C.; Pulido Campaña, A.; García Orta, M.C. y Martínez Porcel, A. « Efectos secundarios de la vacunación antigripal en la edad pediátrica». An Esp Pediatr, supl. 45, vol. 35, octubre 1991: 48.

23. Ipp MM, Gold R, Goldbach M, Maresky DC Saunders N, Greenberg S, Davy T. Efecto de la localización de la inyección y de la longitud de la aguja sobre las reacciones adversas a la vacunación de la DTP Polio a los 18 meses de edad. Pediatrics (ed. española) 1989; 27: 257-260.

24. Edwards KM, Dupont WD, Westrich MK, Plummer WD, Palmer PS, Wright PF, A randomized controlled trail of cold-adapted and inactivated vaccines for the prevention of influenza $A$ disease. J Infect Dis 1994; 169: 68-76.

25. Bautista Rentero D, Tenías Burillo JM, Sabater Pons A, Pérez Bermúdez B, Zanón Viguer $\mathrm{V}$. Comparación de las reacciones adversas a las vacunas antigripales de virus fraccionados y de antígenos de superficie. Rev Esp Salud Pública 1995; 69: 463-468

26. Margolis KL, Poland GA, Nichol KL, MacPherson DS, Meyer JD, Korn JE, Lofgren RP. Frequency of adverse reactions after influenza vaccination. Am J Med 1990; 88: 27-30.

27. Govaert ThME, Dinant GJ, Aretz K, Masurel N, Sprenger MJW, Knottnerus JA. Adverse reactions to influcnza vaccine in elderly people: randomised double blind placebo controlled trial. BMJ 1993: 307: 988-990.

28. Dolin R. Gripe. En: Isselbacher KJ, Braunwald E.m Wilson JD, Martin JB, Fauci AS, Kasper DL. Harrison. Principios de Medicina Interna. Ed. Interamericana-McGraw-Hill, Madrid 1994: $946-$ 951.

29. Dowdle WR. The 1976 experience. J Infect Dis 1997: 176 (suppl 1): 69-72.

30. Delgado Rubio, A. et al.. «Sindrome de Guillain-Barré». Pediatría Clínica 2, vol. 3, Bilbao; 1988, p. 6577. 
31. Viñas A, Campos A, Vilanova JM, Pie M, Vaca MA, Picado M, Bonastre M, Roca A. Programa de vacunación antigripal dirigido a la población infantil. An Esp Pediatr 1994; supl 63: 170.

32. De La Flor, J.; Freizas, F.; Hernández, V.; Ridao, M. L.; Sabriá, J. y Soler, R. M. «Exito de la campaña de vacunación antigripal en la edad pediátrica promovida desde el Centro de Salud». An Esp Pediatr, supl. 45, vol. 35, octubre 1991: 48.

33. Gavira Iglesias FJ, Rodrígue z Lópe z FC, Berni Maestre RM. Análisis de una campaña de vacunación antigripal en el medio rural. Rev San Hig Púb 1987: 61: 759-781.

34. Gastón Morata JL, Aguado Mingorance JA, García Camacho I, Burgos Gámez G. Vacunación antigripal: estudio de satisfacción en una población vacunada. Rev San Hig Púb 1990; 64: 693-703.

35. Monto AS, Iacuzio DA, La Montagne JR. Pandemic influenza-confronting a reemergent threat. J Infect Dis 1997; 176 (suppl 1): 1-3.

36. Patriarca PA, Cox NJ. Influenza pandemic preparedness plan for the United States. J Infect Dis 1997; 176 (suppl 1): 4-7.

37. Hampson AW. Surveillance for pandemic influenza. J Infect Dis 1997; 176 (suppl 1): 8-13.

38. Webster RG. Predictions for future human influenza pandemics. J Infect Dis 1997; 176 (suppl 1): 14-19.

39. Palache AM, Brands R, van Scharrenburg GJM. Immunogenicity and reactogenicity of influenza subunit vaccines produced in MDCK cells or fertilized chicken eggs. J Infect Dis 1997; 176 (suppl 1): 20-22.

40. Schulze IT. Effects of glycosilation on the properties and functions of influenza virus hemaglutinin. J Infect Dis 1997; 176 (suppl 1): 24-28.
41. Kilbourne DE. Perspectives on pandemics: a rescarch agcnda. J Infect Dis 1997; 176 (suppl 1): 29-31.

42. Monto AS. Prospects for pandemic influenza control with currently available vaccines and antivirals. J Infect Dis 1997: 176 (suppl 1): 32-37.

43. Couch RB, Keitel WA, Cate TR. Improvement of inactivated influenza virus vaccines. $J$ Infect Dis 1997; 176 (suppl 1): 38-44.

44. Palese P, Zavala F, Muster T, Nussemzweig RS, García-Sastre A. Development of novel influenza virus vaccines and vectors. J Infect Dis 1997; 176 (suppl 1): 45-49.

45. Robinson HL, Boyle CA, Feltquate DM, Morin MJ, Santoro JC, Webster RG. DNA immunization for influenza virus: studies using hemagglutininand nucleoprotein-expressing DNAs. J Infect Dis 1997; 176 (suppl 1): 50-55.

46. Hayden FG. Antivirals for pandemic influenza. J Infect Dis 1997; 176 (suppl 1): 56-61.

47. Luo M, Air GM, Brouillette WJ. Design of aromatic inhibitors of influenza virus neuraminidase. J Infect Dis 1997; 176 (suppl 1): 62-65.

48. Colacino JM, Laver WG, Air GM. Selection of influenza $A$ and $B$ viruses for resistance to 4-guanidino-neu5Ac2en in cell culture. J Infect Dis 1997; 176 (suppl 1): 66-68.

49. Panel de expertos. Pandemic influenza: confronting a re-emergent threat. Workshop 1 a 6 : summaries and recommendations. J Infect Dis 1997; 176 (suppl 1): 73-86.

50. Cox NJ. Panel summary of international pandemic influenza plans. J Infect Dis 1997; 176 (suppl 1): 87-88. 